OPEN ACCESS

Edited by:

Mike P. Wattjes,

VU University Medical Center,

Netherlands

Reviewed by:

Stefan Ropele,

Medical University of Graz, Austria

Jesper Hagemeier,

Buffalo Neuroimaging Analysis

Center, United States

*Correspondence:

David Pitt

david.pitt@yale.edu

Specialty section:

This article was submitted to Multiple Sclerosis and Neuroimmunology, a section of the journal

Frontiers in Immunology

Received: 21 November 2017

Accepted: 29 January 2018

Published: 19 February 2018

Citation:

Gillen KM, Mubarak M, Nguyen TD and Pitt D (2018) Significance and

In Vivo Detection of Iron-Laden Microglia in White Matter Multiple

Sclerosis Lesions.

Front. Immunol. 9:255.

doi: 10.3389/fimmu.2018.00255

\section{Significance and In Vivo Detection of Iron-Laden Microglia in White Matter Multiple Sclerosis Lesions}

\author{
Kelly M. Gillen ${ }^{1}$, Mayyan Mubarak², Thanh D. Nguyen ${ }^{1}$ and David Pitt ${ }^{2 *}$ \\ ${ }^{1}$ Department of Radiology, Weill Cornell Medicine, New York, NY, United States, ${ }^{2}$ Department of Neurology, Yale School of \\ Medicine, New Haven, CT, United States
}

Microglia are resident immune cells that fulfill protective and homeostatic functions in the central nervous system (CNS) but may also promote neurotoxicity in the aged brain and in chronic disease. In multiple sclerosis (MS), an autoimmune demyelinating disease of the CNS, microglia and macrophages contribute to the development of white matter lesions through myelin phagocytosis, and possibly to disease progression through diffuse activation throughout myelinated white matter. In this review, we discuss an additional compartment of myeloid cell activation in MS, i.e., the rim and normal adjacent white matter of chronic active lesions. In chronic active lesions, microglia and macrophages may contain high amounts of iron, express markers of proinflammatory polarization, are activated for an extended period of time (years), and drive chronic tissue damage. Ironpositive myeloid cells can be visualized and quantified with quantitative susceptibility mapping (QSM), a magnetic resonance imaging technique. Thus, QSM has potential as an in vivo biomarker for chronic inflammatory activity in established white matter MS lesions. Reducing chronic inflammation associated with iron accumulation using existing or novel MS therapies may impact disease severity and progression.

Keywords: multiple sclerosis, microglia, magnetic resonance imaging, quantitative susceptibility mapping, myelin, iron

\section{INTRODUCTION TO MICROGLIA}

Microglia are resident immune cells of the central nervous system (CNS) responsible for homeostatic functions, including neurogenesis and clearance of cellular debris, and for responding to injury and infection (1-3). In a resting state, microglia have a ramified appearance with thin processes that survey the surrounding microenvironment (4-6). Following activation, microglia and macrophages can adopt a spectrum of phenotypes composed of pro-inflammatory (M1) and anti-inflammatory (M2) functions (7-11). The classically activated M1 phenotype is characterized by expression of pro-inflammatory cytokines (e.g., IL-1 $\beta$, TNF- $\alpha$ ), and induction of nitric-oxide synthase $(6,12,13)$, while the M2 phenotype is characterized by secretion of anti-inflammatory cytokines (e.g., IL-10), and neurotrophic and angiogenic factors $(6,12,13)$. Changes in activation status and cell signaling induce morphological changes, motility, and phagocytosis (14). Even though microglia and macrophages express similar cell surface markers and can be morphologically indistinguishable (13, 14), they originate from distinct progenitors: macrophages are monocyte-derived, while microglia arise from differentiated yolk sac erythromyeloid precursors (15-17). Macrophages have been widely studied in vivo and in vitro; however, the functions of microglia are still not well defined, including their roles in inflammatory diseases such as multiple sclerosis (MS). 


\section{MS LESION PATHOLOGY}

Multiple sclerosis is a chronic inflammatory disease of the CNS, characterized by focal demyelination, that is caused by an autoimmune response to self-antigens (18). MS is the most common cause of non-traumatic neurological disability in young adults, affecting more than 2.3 million people worldwide. The disease usually starts with episodes of neurological dysfunction that remit spontaneously, a course that is termed relapsing remitting MS (RRMS). One to two decades into RRMS, most MS patients enter a secondary progressive phase, where relapses are replaced by slow, irreversible progression of neurological disability (19). Significant strides have been made in understanding the pathophysiology of relapses; however, progression remains largely unexplained. Multiple lines of evidence suggest that progressive MS is associated with chronic activation of the CNS innate immune system (20-22).

Inflammatory demyelinating lesions are a pathological hallmark of RRMS. Acutely demyelinating lesions are characterized by a breach of the blood-brain barrier (BBB), infiltration with leukocytes, and breakdown and phagocytosis of myelin (23). Acute lesions evolve into chronic active lesions, which contain a demyelinated, gliotic lesion center, and activated microglia and macrophages at the lesion edge. Depending on the activation status and phagocytotic activity of myeloid cells at the lesion rim, chronic active lesions may stay dormant or continue to slowly expand (Figure 1) (24). Eventually, chronic active lesions become chronic silent, i.e., they no longer contain inflammatory cells (25). Myelin-laden, foamy macrophages in the center and inner rim of acute lesions express anti-inflammatory cytokines (26), suggesting that myelin phagocytosis induces an anti-inflammatory phenotype, which may contribute to the eventual resolution of inflammation. The M2-inducing properties of myelin uptake have been confirmed in cultured monocyte-derived macrophages and in mouse models of spinal-cord injury (26-29).

A more recent study posits that myelin-containing macrophages in actively demyelinating areas exhibit a mixed phenotype expressing both M1 and M2 markers, including CD40, CD86, CD64, and CD32 (M1), as well as mannose receptor and CD163 (M2) (30). Moreover, at the rim of chronic active lesions, microglia lack expression of M2 markers, suggesting that the M2 component becomes extinguished once the lesion progresses from acutely demyelinating to chronic active (30). M2 markers are also expressed by microglia and macrophages during remyelination (31).

\section{THE ROLE OF IRON IN THE CNS}

A striking feature of chronic active MS lesions is that iron is highly enriched in activated microglia and macrophages at the lesion edge (27), which has implications for their function and in vivo detection in MS patients, as discussed below. Iron acts as a cofactor for various enzymatic reactions, and is essential for normal brain function, specifically the synthesis and maintenance of myelin $(32,33)$. Accordingly, in the CNS, iron is present primarily in oligodendrocytes and myelin (34), where it is stored predominantly in the redox-inactive ferric $\left(\mathrm{Fe}^{3+}\right)$ form within ferritin. Unbound ferrous iron $\left(\mathrm{Fe}^{2+}\right)$ can catalyze production of reactive oxygen species (ROS) through the Fenton reaction $(35,36)$. This cytotoxic process is minimized through a highly coordinated process that involves specific iron transport, uptake, and storage proteins, including transferrin, transferrin receptor, hepcidin, divalent metal transporter 1 , ferroportin, and ferritin $(37,38)$.

In the normal aging brain, iron levels increase in the cortex, cerebellum, and deep gray matter $(39,40)$. Accelerated accumulation of iron in the basal ganglia and motor cortex have been demonstrated in several CNS disorders such as Parkinson's disease (41), Alzheimer's disease (42), Huntington's disease (43, 44), amyotrophic lateral sclerosis (45), and MS (46-52). While iron accumulation correlates with disease progression, the pathological processes have not been well delineated. Iron accumulation may be associated with excess ferrous iron and ROS production (53), but it is unknown whether iron accumulation is the cause

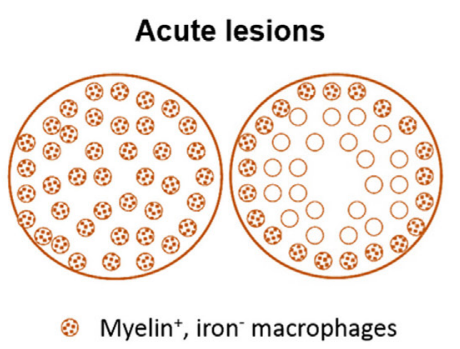

Open BBB

Gadolinium enhancement Active demyelination M2 marker expression by macrophages
Chronic active lesions

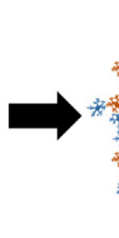

* Myelin, iron ${ }^{+}$microglia
Chronic silent lesions

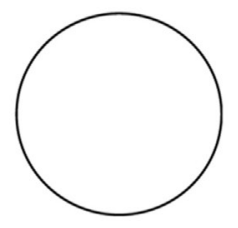

Closed BBB

No enhancement/low susceptibility No demyelination No inflammatory cells

FIGURE 1 | Schematic of white-matter lesion development and its representation with quantitative susceptibility mapping (QSM). Acutely demyelinating lesions are Gd enhancing on T1w imaging and contain M2-activated macrophages. Acute lesions eventually progress to chronic active lesions that may contain iron+ microglia/ macrophages at the lesion rim and express M1 activation markers. These lesions are typically non-enhancing and appear hyperintense with respect to normal appearing white matter (NAWM) on susceptibility weighted imaging. Chronic silent lesions lack inflammatory cells and their susceptibility is similar to that of nearby NAWM. 
of tissue damage or occurs secondary to neurodegeneration. Oligodendrocytes, oligodendrocyte progenitors, and neurons are particularly sensitive to ROS, as they are unable, unlike astrocytes, to produce high levels of the free-radical scavenger glutathione (54-56). Glutathione also inhibits an iron-dependent form of programmed cell death, ferroptosis, triggered by iron overload (57-60). Furthermore, high iron induces glutamate release by neurons $(61,62)$, which potentially leads to excitotixicity in neurons and oligodendrocytes.

In MS, increased iron in deep gray matter has been inferred from T2 hypointensities on magnetic resonance imaging (MRI), although changes in T2 signal can be caused by multiple factors, including inflammation and edema. Clinically, deep gray matter T2 hypointensities correlated with brain atrophy, disability progression, and cognitive impairment (47-50, 63). In a study that used quantitative susceptibility mapping (QSM) rather than T2 signal to map iron content, magnetic susceptibility in basal ganglia of MS patients correlated with decreased performance on basal ganglia-reliant neuropsychological tasks (64). Histologically, iron was present in deep gray matter primarily in oligodendrocytes and myelin fibers, and to a lesser extent, in microglia and astrocytes; In contrast to imaging studies, a statistically significant iron increase in deep gray matter of MS patients compared with controls could not be demonstrated (65).

\section{IRON IS A MARKER OF CHRONIC INFLAMMATORY MS LESIONS}

A second site of iron accumulation in MS is in activated microglia/macrophages at the rim of chronic active lesions $(27,66,67)$. Myeloid cells play important roles in iron homeostasis, including iron recycling through erythrophagocytosis (68) and induction of inflammatory hypoferremia (69), which bolsters resistance to infectious diseases. Since microbes depend on iron for growth and survival, its sequestration by macrophages is an important inflammatory response $(70,71)$. In activated macrophages, accumulation of iron is promoted by IL- 6 and IL- $1 \beta$, which induce the iron regulatory hormone hepcidin $(69,72,73)$. Thus, iron accumulation is partially regulated by pro-inflammatory cytokines, consistent with the observation that iron uptake correlates with functional polarization of macrophages/microglia. Classically activated (M1) macrophages in vitro take up more iron than M2 or M0 macrophages $(27,74,75)$, in keeping with the low iron levels in myelin-laden, M2-polarized macrophages in vitro and in acutely demyelinating lesions $(26,27)$. We have recently confirmed that iron uptake is enhanced in human-induced pluripotent stem cell-derived microglia following M1 polarization (unpublished data). Moreover, iron induces a persistent pro-inflammatory state in macrophages in chronic venous ulcers and spinal-cord injury, thus preventing the physiologic switch from M1 to M2 activation associated with wound healing $(74,75)$. While the direct effects of iron accumulation on macrophage activation are not completely understood, one proposed mechanism is that high intracellular iron activates nuclear factor-kappa $\mathrm{B}(\mathrm{NF}-\kappa \mathrm{B})$, leading to expression of NF- $\mathrm{BB}$ target genes including pro-inflammatory cytokines (76). In additional preliminary data, we found that iron-positive, chronic active lesions contained substantially more activated microglia/macrophages that expressed iNOS, ferritin, and the phagocytosis marker, MerTK, compared with iron-negative, chronic active lesions.

The source of iron in MS lesions is unknown, but it is tempting to speculate that the destruction of iron-rich myelin and oligodendrocytes during lesion formation leads to iron release into the extracellular space and eventual uptake by myeloid cells. Hametner and colleagues have shown that iron is decreased in oligodendrocytes within NAWM in patients with longstanding disease (67), suggesting a shift of iron from oligodendrocytes to microglia, which may impair the ability of oligodendrocytes to maintain myelin or to remyelinate.

\section{DETECTING CHRONIC INFLAMMATION IN MS PATIENTS}

Magnetic resonance imaging is a valuable tool for diagnosing MS and monitoring inflammatory activity in MS patients. Acutely demyelinating lesions can be visualized through gadolinium that accumulates within lesions with temporary breakdown of the BBB (77-79). However, gadolinium enhancement offers only a small window into early inflammatory activity, as the BBB closes within weeks of lesion formation (Figure 1). Gadolinium enhancement in MS lesions is preceded and outlasted by infiltration with immune cells. This has been demonstrated in MS patients with positron emission tomography (PET) imaging studies using radioactive ligands for the $18-\mathrm{kDa}$ translocator protein (TSPO) (80), and with MRI of ultra-small iron-oxide particles that were injected peripherally and detected in activated monocytes/macrophages infiltrating the lesions (81). These imaging results are consistent with histological studies indicating that significant inflammatory activity occurs behind a closed BBB (82).

The therapeutic goal of managing MS patients is to completely suppress CNS inflammation. Thus the inability to detect chronic inflammation in MS with conventional MRI techniques is a significant, unmet need in clinical practice. While TSPO-PET imaging allows for assessment of glial cell activation, PET imaging requires significant infrastructure, is costly, and involves patient exposure to radioactivity, all of which make this method unsuitable for broad use in clinical practice. A solution to the problem of visualizing activated microglia/macrophages in lesions is to exploit their high iron content using novel MRI techniques.

\section{QSM IN MS}

Tissue can become magnetized in response to a magnetic field, and the extent of magnetization is known as susceptibility, which arises from unpaired electrons in iron or external sources such as contrast agents. MRI permits visualization of tissue susceptibility through gradient echo (GRE) and phase imaging. These techniques have been used to monitor MS lesions $(27,66,83$, 84 ), but they cannot quantify or localize iron (85). QSM permits visualization of the sizes and shapes of iron sources, delivers precise estimates of iron concentrations, and distinguishes between susceptibility sources such as iron and calcification (85). QSM 
maps both ferrous $\left(\mathrm{Fe}^{2+}\right)$ and the substantially more common ferric $\left(\mathrm{Fe}^{3+}\right)$ iron, but cannot distinguish between the two sources. In addition, the presence of lipid macromolecules such as myelin reduces tissue susceptibility, resulting in increased susceptibility in demyelinated lesions. QSM is now widely used by the imaging research community in applications to detect iron, map bone mineralization and monitor drug bio-distribution delivered by magnetic-core nanocarriers (38, 44, 86-103).

Several studies, including our own, combined QSM or phase imaging of MS autopsy tissue with histological analysis, and confirmed that high tissue susceptibility at the rims of MS lesions correlated approximately with the distribution of iron and CD68 ${ }^{+}$ microglia/macrophages (Figure 2) (24, 27, 66, 83, 104, 105), which contain predominantly ferric iron. In addition, elemental tissue analysis with laser ablation mass spectrometry combined with QSM and IHC of autopsied lesions has established that positive susceptibility values were associated with iron deposition in activated microglia/macrophages (104). In a separate study, X-ray fluorescence imaging and histochemical techniques on autopsied MS brains demonstrated that iron accumulated in microglia/ macrophages in chronic lesions (106). These results demonstrate that white matter lesions with high tissue susceptibility at the lesion rim are indicative of iron-positive microglia/macrophages.

An unresolved challenge regarding QSM is the inability to distinguish between the contributions of iron accumulation and myelin loss to lesion susceptibility $(107,108)$. Both can cause an increase in susceptibility, which generates the need to develop a method to separate the two sources. Birkl et al. addressed the confounding effect of myelin on iron quantification in MS tissue by exploiting the temperature dependency of the susceptibility of paramagnetic iron, which decreases with temperature, while the susceptibility of the diamagnetic myelin remains constant (109). While this technique is well suited for ex vivo research, it cannot be applied to patients. In addition, a study of lesions in MS tissue by Wiggermann et al. (108) that determined the sources of lesion contrast on QSM, found a poor correlation between lesional iron content and QSM. While these findings may be explained in part by the low iron content in the examined lesions, their data suggest that the QSM contrast between lesions and the surrounding NAWM may be driven by pathological changes known to be present in NAWM. Therefore, using NAWM as susceptibility reference, as is common in current practice, can lead to an incorrect interpretation of QSM change. A more reliable reference is cerebrospinal fluid, which consists essentially of water and can provide a uniform zero-reference (110).

In the first study that applied QSM to MS, Langkammer et al. demonstrated in patients with established MS or with clinically isolated syndrome, an isolated MS-like neurological episode, that QSM is more sensitive than $\mathrm{R} 2^{*}$ in the detection of tissue changes in the basal ganglia (107). The authors interpreted the increase in susceptibility as a consequence of increased iron content, but noted that demyelination may play an additive role. In a small clinical imaging study, we demonstrated that patients with active RRMS contained significantly more lesions with high susceptibility on phase imaging than patients with chronic, stable disease (27). Furthermore, we found in a retrospective study, where susceptibility was quantified in white matter lesions of different ages, tissue susceptibility was isointense in Gd-enhancing lesions, and increased rapidly after enhancement subsided, suggesting that lesions acquired iron as they transitioned from an acute to a chronic active state. The elevated susceptibility was stable for approximately 4 years and then decayed to levels similar to that of NAWM (Figure 1) (111). This time course of tissue susceptibility was recently confirmed in a separate longitudinal study with MS patients (112). On a cellular level, the isointense susceptibility in enhancing lesions may be

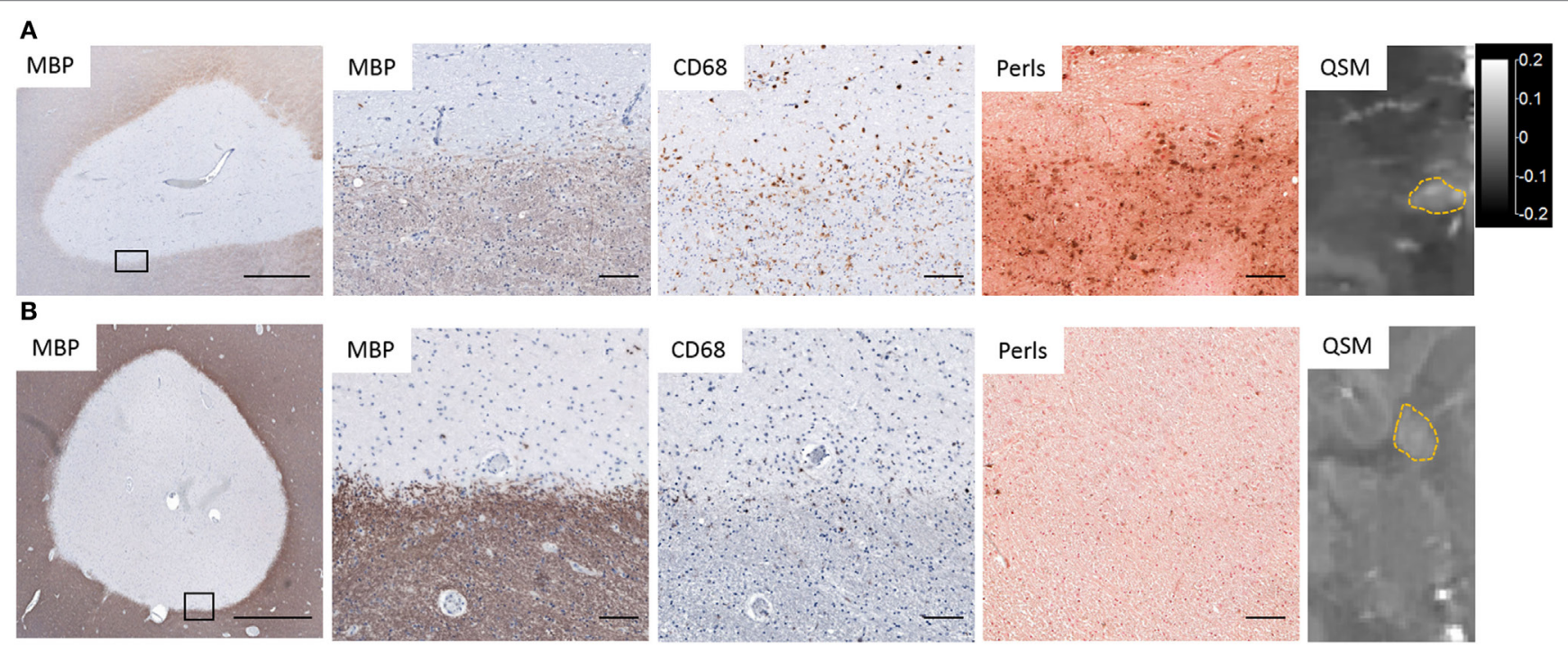

FIGURE 2 | Iron deposition in chronic active lesions corresponding to regions of hyperintensity on quantitative susceptibility mapping (QSM). (A) Iron-positive lesions contain $\mathrm{CD}_{68}{ }^{+}$Perls ${ }^{+}$microglia and macrophages at the lesion rim whose distribution corresponds to hyperintensities on QSM. (B) Iron-negative lesions contain few Perls ${ }^{+}$microglia and have low-tissue susceptibility on QSM. Black rectangles in low magnification images identify the location of higher magnification images. Scale bar in low magnification images $=1,000 \mu \mathrm{m}$. Scale bar in high magnification images $=100 \mu \mathrm{m}$. QSM scale bar is the same for both images and is in ppm (parts per million). 
explained by the reduced capacity of myelin-phagocytosing macrophages to take up iron (27), consistent with the M2-like phenotype of myelin-laden macrophages (26). As the lesion evolves, myelin-laden macrophages continue to break down ingested myelin and eventually exit the lesion center. Activated non- or slowly phagocytosing myeloid cells at the lesion rim accumulate iron and adopt a chronic inflammatory state (75) that may persist for several years $(111,112)$.

In a recent prospective imaging study using phase imaging, persistence of phase rims in white matter lesions was associated with increased lesion T1 hypointensities, a marker for tissue damage (113). In addition, Dal-Bianco et al. reported that white matter lesions with phase-positive rims slowly expanded over time, supporting the idea that iron-positive microglia/ macrophages are associated with chronic, slow inflammatory demyelination (24). It is tempting to speculate that high prevalence of lesions with hyperintense rims is associated with a more severe disease course and/or disease progression; however, these data are not yet available. Prospective studies examining these correlations are currently ongoing at our centers.

The prevalence of white matter lesions with hyperintense rims on QSM and phase imaging varies widely, ranging from 0 (113) to $32 \%(114)$. This variability is unsurprising given the different imaging techniques, resolutions, and patient cohorts used in these studies. An imaging study on MS patients from our group revealed that $21 \%$ of lesions visible on QSM had a hyperintense rim, and 79\% displayed homogenous or heterogenous distribution patterns (115). Our preliminary data from a combined imaging and histology study of MS brain tissue suggest that heterogenous QSM patterns were typically associated with the presence of heme within enlarged blood vessels in MS lesions. We have currently no data to explain homogenously increased susceptibility throughout lesions, but hypothesize that absence of myelin drives the susceptibility increase in these lesions.

In summary, although susceptibility weighted imaging cannot distinguish between iron accumulation and myelin loss, increased susceptibility at the lesion rim likely represents chronically activated, iron-positive microglia and macrophages. Moreover, longitudinal imaging studies of MS patients using QSM suggest that iron-positive lesions persist for many years and are associated with increased tissue loss and slow expansion $(24,113)$.

\section{CLINICAL IMPLICATIONS}

Based on the above studies, high tissue susceptibility in white-matter lesions may be useful as a biomarker for chronic active lesions. Although the detrimental effect of smoldering, low-grade inflammation on the surrounding parenchyma has

\section{REFERENCES}

1. Lull ME, Block ML. Microglial activation and chronic neurodegeneration. Neurotherapeutics (2010) 7(4):354-65. doi:10.1016/j.nurt.2010. 05.014

2. ElAli A, Rivest S. Microglia ontology and signaling. Front Cell Dev Biol (2016) 4:72. doi:10.3389/fcell.2016.00072

3. Goldmann T, Prinz M. Role of microglia in CNS autoimmunity. Clin Dev Immunol (2013) 2013:208093. doi:10.1155/2013/208093 been demonstrated $(24,113)$, it is unknown if the presence of hyperintense susceptibility rim lesions predict a more severe clinical course; studies are ongoing that examine this association. Moreover, we are testing the ability of current MS treatments to remove iron from existing white matter lesions in MS patients. Of particular interest are MS medications that penetrate the $\mathrm{BBB}$ and act directly on microglia, such as dimethyl fumarate (Tecfidera ${ }^{\mathrm{TM}}$ ), fingolimod (Gilenya ${ }^{\mathrm{TM}}$ ), and Laquinimod (116-118).

Since QSM can be rapidly and reliably acquired with standard field strength (3T) MRI scanners, it can easily be implemented in clinical settings and broadly used for MS patient care. Thus, ironsensitive imaging may become an important imaging modality to detect chronic inflammation in MS patients that appear stable on conventional MRI but have a high burden of lesional microglial activation.

\section{SUMMARY AND OUTLOOK}

We reviewed iron metabolism in macrophages/microglia, iron accumulation in MS lesions, and iron-sensitive imaging studies in MS tissue and patients. Iron is taken up by M1-polarized macrophages/microglia, which may further increase their pro-inflammatory properties. Iron can be visualized with MR sequences sensitive to tissue susceptibility. In MS patients, high susceptibility in white matter lesions can persist for several years after lesion formation, suggesting that iron-positive myeloid cells are present in MS lesions for prolonged periods of time. In addition, high susceptibility is associated with increase tissue loss and lesion expansion.

Therefore, the emerging picture suggests that iron-positive microglia and macrophages in chronic active MSlesions constitute a distinct, previously unappreciated inflammatory compartment that may be a significant contributor to tissue damage, disease severity, and/or progression. Reducing chronic inflammation associated with iron deposition in MS lesions with existing or novel MS therapies may be of high benefit to patients.

\section{AUTHOR CONTRIBUTIONS}

KG and DP wrote the manuscript. MM, KG, and TDN conducted experiments. All authors contributed to analysis and interpretation.

\section{FUNDING}

This work was supported by the National Multiple Sclerosis Society (RG-1610-26049 to DP, RG-1062-07671 to TDN), and the National Institutes of Health (R01 NS102267, R01 NS090464, and R01 NS095562 to DP).

4. Nimmerjahn A, Kirchhoff F, Helmchen F. Resting microglial cells are highly dynamic surveillants of brain parenchyma in vivo. Science (2005) 308(5726):1314-8. doi:10.1126/science.1110647

5. Davalos D, Grutzendler J, Yang G, Kim JV, Zuo Y, Jung S, et al. ATP mediates rapid microglial response to local brain injury in vivo. Nat Neurosci (2005) 8(6):752-8. doi:10.1038/nn1472

6. Thompson KK, Tsirka SE. The diverse roles of microglia in the neurodegenerative aspects of central nervous system (CNS) autoimmunity. Int J Mol Sci (2017) 18(3):504. doi:10.3390/ijms18030504 
7. Mosser DM, Edwards JP. Exploring the full spectrum of macrophage activation. Nat Rev Immunol (2008) 8(12):958-69. doi:10.1038/nri2448

8. Murray PJ, Wynn TA. Protective and pathogenic functions of macrophage subsets. Nat Rev Immunol (2011) 11(11):723-37. doi:10.1038/nri3073

9. Stout RD, Jiang C, Matta B, Tietzel I, Watkins SK, Suttles J. Macrophages sequentially change their functional phenotype in response to changes in microenvironmental influences. JImmunol (2005) 175(1):342-9. doi:10.4049/jimmunol.175.1.342

10. Kim CC, Nakamura MC, Hsieh CL. Brain trauma elicits non-canonical macrophage activation states. J Neuroinflammation (2016) 13(1):117. doi:10.1186/s12974-016-0581-z

11. Murray PJ, Allen JE, Biswas SK, Fisher EA, Gilroy DW, Goerdt S, et al. Macrophage activation and polarization: nomenclature and experimental guidelines. Immunity (2014) 41(1):14-20. doi:10.1016/j.immuni.2014.06.008

12. Roszer $\mathrm{T}$. Understanding the mysterious $\mathrm{M} 2$ macrophage through activation markers and effector mechanisms. Mediators Inflamm (2015) 2015:816460. doi:10.1155/2015/816460

13. Luo C, Jian C, Liao Y, Huang Q, Wu Y, Liu X, et al. The role of microglia in multiple sclerosis. Neuropsychiatr Dis Treat (2017) 13:1661-7. doi:10.2147/ NDT.S140634

14. Bogie JF, Stinissen P, Hendriks JJ. Macrophage subsets and microglia in multiple sclerosis. Acta Neuropathol (2014) 128(2):191-213. doi:10.1007/ s00401-014-1310-2

15. Ginhoux F, Greter M, Leboeuf M, Nandi S, See P, Gokhan S, et al. Fate mapping analysis reveals that adult microglia derive from primitive macrophages. Science (2010) 330(6005):841-5. doi:10.1126/science.1194637

16. Schulz C, Gomez Perdiguero E, Chorro L, Szabo-Rogers H, Cagnard N, Kierdorf $\mathrm{K}$, et al. A lineage of myeloid cells independent of Myb and hematopoietic stem cells. Science (2012) 336(6077):86-90. doi:10.1126/ science.1219179

17. Kierdorf K, Erny D, Goldmann T, Sander V, Schulz C, Perdiguero EG, et al. Microglia emerge from erythromyeloid precursors via Pu.1- and Irf8-dependent pathways. Nat Neurosci (2013) 16(3):273-80. doi:10.1038/ nn. 3318

18. Nylander A, Hafler DA. Multiple sclerosis. J Clin Invest (2012) 122(4):1180-8. doi:10.1172/JCI58649

19. Love SLD, Ellison DW. Greenfield's Neuropathology. London: CRC Press (2008).

20. Kutzelnigg A, Lucchinetti CF, Stadelmann C, Brück W, Rauschka H, Bergmann $\mathrm{M}$, et al. Cortical demyelination and diffuse white matter injury in multiple sclerosis. Brain (2005) 128(Pt 11):2705-12. doi:10.1093/brain/ awh641

21. Gandhi R, Laroni A, Weiner HL. Role of the innate immune system in the pathogenesis of multiple sclerosis. J Neuroimmunol (2010) 221(1-2):7-14. doi:10.1016/j.jneuroim.2009.10.015

22. Karni A, Abraham M, Monsonego A, Cai G, Freeman GJ, Hafler D, et al. Innate immunity in multiple sclerosis: myeloid dendritic cells in secondary progressive multiple sclerosis are activated and drive a proinflammatory immune response. J Immunol (2006) 177(6):4196-202. doi:10.4049/ jimmunol.177.6.4196

23. Frohman EM, Racke MK, Raine CS. Multiple sclerosis - the plaque and its pathogenesis. N Engl J Med (2006) 354(9):942-55. doi:10.1056/ NEJMra052130

24. Dal-Bianco A, Grabner G, Kronnerwetter C. Slow expansion of multiple sclerosis iron rim lesions: pathology and $7 \mathrm{~T}$ magnetic resonance imaging. Acta Neuropathol (2017) 133(1):25-42. doi:10.1007/s00401-016-1636-z

25. Kuhlmann T, Ludwin S, Prat A, Antel J, Bruck W, Lassmann H. An updated histological classification system for multiple sclerosis lesions. Acta Neuropathol (2017) 133(1):13-24. doi:10.1007/s00401-016-1653-y

26. Boven LA, Van Meurs M, Van Zwam M, Wierenga-Wolf A, Hintzen RQ, Boot RG, et al. Myelin-laden macrophages are anti-inflammatory, consistent with foam cells in multiple sclerosis. Brain (2006) 129(Pt 2):517-26. doi:10.1093/brain/awh707

27. Mehta V, Pei W, Yang G, Li S, Swamy E, Boster A, et al. Iron is a sensitive biomarker for inflammation in multiple sclerosis lesions. PLoS One (2013) 8(3):e57573. doi:10.1371/journal.pone.0057573

28. Liu Y, Hao W, Letiembre $M$, Walter S, Kulanga M, Neumann $H$, et al. Suppression of microglial inflammatory activity by myelin phagocytosis: role of p47-PHOX-mediated generation of reactive oxygen species. J Neurosci (2006) 26(50):12904-13. doi:10.1523/JNEUROSCI.2531-06.2006

29. van Rossum D, Hilbert S, Strassenburg S, Hanisch UK, Bruck W. Myelinphagocytosing macrophages in isolated sciatic and optic nerves reveal a unique reactive phenotype. Glia (2008) 56(3):271-83. doi:10.1002/ glia.20611

30. Vogel DY, Vereyken EJ, Glim JE, Heijnen PD, Moeton M, van der Valk P, et al. Macrophages in inflammatory multiple sclerosis lesions have an intermediate activation status. J Neuroinflammation (2013) 10:35. doi:10.1186/ 1742-2094-10-35

31. Miron VE, Boyd A, Zhao JW, Yuen TJ, Ruckh JM, Shadrach JL, et al. M2 microglia and macrophages drive oligodendrocyte differentiation during CNS remyelination. Nat Neurosci (2013) 16(9):1211-8. doi:10.1038/nn.3469

32. Connor JR, Menzies SL. Cellular management of iron in the brain. J Neurol Sci (1995) 134(Suppl):33-44. doi:10.1016/0022-510X(95)00206-H

33. Todorich B, Pasquini JM, Garcia CI, Paez PM, Connor JR. Oligodendrocytes and myelination: the role of iron. Glia (2009) 57(5):467-78. doi:10.1002/ glia.20784

34. Connor JR, Menzies SL, St Martin SM, Mufson EJ. Cellular distribution of transferrin, ferritin, and iron in normal and aged human brains. J Neurosci Res (1990) 27(4):595-611. doi:10.1002/jnr.490270421

35. Fridovich I. Fundamental aspects of reactive oxygen species, or what's the matter with oxygen? Ann N Y Acad Sci (1999) 893:13-8. doi:10.111 1/j.1749-6632.1999.tb07814.x

36. Valko M, Rhodes CJ, Moncol J, Izakovic M, Mazur M. Free radicals, metals and antioxidants in oxidative stress-induced cancer. Chem Biol Interact (2006) 160(1):1-40. doi:10.1016/j.cbi.2005.12.009

37. Hentze MW, Muckenthaler MU, Andrews NC. Balancing acts: molecular control of mammalian iron metabolism. Cell (2004) 117(3):285-97. doi:10.1016/S0092-8674(04)00343-5

38. Wang Y, Spincemaille P, Liu Z, Dimov A, Deh K, Li J, et al. Clinical quantitative susceptibility mapping (QSM): biometal imaging and its emerging roles in patient care. J Magn Reson Imaging (2017) 46(4):951-71. doi:10.1002/ jmri.25693

39. Pujol J, Junqué C, Vendrell P, Grau JM, Martí-Vilalta JL, Olivé C, et al. Biological significance of iron-related magnetic resonance imaging changes in the brain. Arch Neurol (1992) 49(7):711-7. doi:10.1001/ archneur.1992.00530310053012

40. Zecca L, Youdim MB, Riederer P, Connor JR, Crichton RR. Iron, brain ageing and neurodegenerative disorders. Nat Rev Neurosci (2004) 5(11):863-73. doi:10.1038/nrn1537

41. Jiang H, Wang J, Rogers J, Xie J. Brain iron metabolism dysfunction in Parkinson's disease. Mol Neurobiol (2017) 54(4):3078-101. doi:10.1007/ s12035-016-9879-1

42. Prakash A, Dhaliwal GK, Kumar P, Majeed AB. Brain biometals and Alzheimer's disease - boon or bane? Int J Neurosci (2017) 127(2):99-108. do i: $10.3109 / 00207454.2016 .1174118$

43. Domínguez JF, Ng AC, Poudel G, Stout JC, Churchyard A, Chua P, et al. Iron accumulation in the basal ganglia in Huntington's disease: cross-sectional data from the IMAGE-HD study. J Neurol Neurosurg Psychiatry (2016) 87(5):545-9. doi:10.1136/jnnp-2014-310183

44. van Bergen JM, Hua J, Unschuld PG, Lim IA, Jones CK, Margolis RL, et al. Quantitative susceptibility mapping suggests altered brain iron in premanifest huntington disease. AJNR Am J Neuroradiol (2016) 37(5):789-96. doi:10.3174/ajnr.A4617

45. Kwan JY, Jeong SY, Van Gelderen P, Deng HX, Quezado MM, Danielian LE, et al. Iron accumulation in deep cortical layers accounts for MRI signal abnormalities in ALS: correlating 7 tesla MRI and pathology. PLoS One (2012) 7(4):e35241. doi:10.1371/journal.pone.0035241

46. Stephenson E, Nathoo N, Mahjoub Y, Dunn JF, Yong VW. Iron in multiple sclerosis: roles in neurodegeneration and repair. Nat Rev Neurol (2014) 10(8):459-68. doi:10.1038/nrneurol.2014.118

47. Neema M, Arora A, Healy BC, Guss ZD, Brass SD, Duan Y, et al. Deep gray matter involvement on brain MRI scans is associated with clinical progression in multiple sclerosis. J Neuroimaging (2009) 19(1):3-8. doi:10.1111/ j.1552-6569.2008.00296.x

48. Bermel RA, Puli SR, Rudick RA, Weinstock-Guttman B, Fisher E, Munschauer FE III, et al. Prediction of longitudinal brain atrophy in multiple 
sclerosis by gray matter magnetic resonance imaging T2 hypointensity. Arch Neurol (2005) 62(9):1371-6. doi:10.1001/archneur.62.9.1371

49. Bakshi R, Benedict RH, Bermel RA, Caruthers SD, Puli SR, Tjoa CW, et al. $\mathrm{T} 2$ hypointensity in the deep gray matter of patients with multiple sclerosis: a quantitative magnetic resonance imaging study. Arch Neurol (2002) 59(1):62-8. doi:10.1001/archneur.59.1.62

50. Bakshi R, Dmochowski J, Shaikh ZA, Jacobs L. Gray matter T2 hypointensity is related to plaques and atrophy in the brains of multiple sclerosis patients. J Neurol Sci (2001) 185(1):19-26. doi:10.1016/S0022-510X(01)00477-4

51. Bakshi R, Shaikh ZA, Janardhan V. MRI T2 shortening ('black T2') in multiple sclerosis: frequency, location, and clinical correlation. Neuroreport (2000) 11(1):15-21. doi:10.1097/00001756-200001170-00004

52. Bagnato F, Hametner S, Welch EB. Visualizing iron in multiple sclerosis. Magn Reson Imaging (2013) 31(3):376-84. doi:10.1016/j.mri.2012.11.011

53. Oshiro S, Morioka MS, Kikuchi M. Dysregulation of iron metabolism in Alzheimer's disease, Parkinson's disease, and amyotrophic lateral sclerosis. Adv Pharmacol Sci (2011) 2011:378278. doi:10.1155/2011/378278

54. Thorburne SK, Juurlink BH. Low glutathione and high iron govern the susceptibility of oligodendroglial precursors to oxidative stress. J Neurochem (1996) 67(3):1014-22. doi:10.1046/j.1471-4159.1996.67031014.x

55. Makar TK, Nedergaard M, Preuss A, Gelbard AS, Perumal AS, Cooper AJ. Vitamin E, ascorbate, glutathione, glutathione disulfide, and enzymes of glutathione metabolism in cultures of chick astrocytes and neurons: evidence that astrocytes play an important role in antioxidative processes in the brain. J Neurochem (1994) 62(1):45-53. doi:10.1046/j.1471-4159.1994.62010045.x

56. Iwata-Ichikawa E, Kondo Y, Miyazaki I, Asanuma M, Ogawa N. Glial cells protect neurons against oxidative stress via transcriptional up-regulation of the glutathione synthesis. J Neurochem (1999) 72(6):2334-44. doi:10.1046/j.1471-4159.1999.0722334.x

57. Yang WS, Stockwell BR. Synthetic lethal screening identifies compounds activating iron-dependent, nonapoptotic cell death in oncogenic-RAS-harboring cancer cells. Chem Biol (2008) 15(3):234-45. doi:10.1016/ j.chembiol.2008.02.010

58. Dixon SJ, Lemberg KM, Lamprecht MR, Skouta R, Zaitsev EM, Gleason CE, et al. Ferroptosis: an iron-dependent form of nonapoptotic cell death. Cell (2012) 149(5):1060-72. doi:10.1016/j.cell.2012.03.042

59. Chen L, Hambright WS, Na R, Ran Q. Ablation of the ferroptosis inhibitor glutathione peroxidase 4 in neurons results in rapid motor neuron degeneration and paralysis. J Biol Chem (2015) 290(47):28097-106. doi:10.1074/ jbc.M115.680090

60. Doll S, Proneth B, Tyurina YY, Panzilius E, Kobayashi S, Ingold I, et al. ACSL4 dictates ferroptosis sensitivity by shaping cellular lipid composition. Nat Chem Biol (2017) 13(1):91-8. doi:10.1038/nchembio.2239

61. Schipper HM. Neurodegeneration with brain iron accumulation - clinical syndromes and neuroimaging. Biochim Biophys Acta (2012) 1822(3):350-60. doi:10.1016/j.bbadis.2011.06.016

62. McGahan MC, Harned J, Mukunnemkeril M, Goralska M, Fleisher L, Ferrell JB. Iron alters glutamate secretion by regulating cytosolic aconitase activity. Am J Physiol Cell Physiol (2005) 288(5):C1117-24. doi:10.1152/ ajpcell.00444.2004

63. Zhang Y, Metz LM, Yong VW, Mitchell JR. 3T deep gray matter T2 hypointensity correlates with disability over time in stable relapsing-remitting multiple sclerosis: a 3-year pilot study. J Neurol Sci (2010) 297(1-2):76-81. doi:10.1016/j.jns.2010.07.014

64. Schmalbrock P, Prakash RS, Schirda B, Janssen A, Yang GK, Russell M, et al. Basal ganglia iron in patients with multiple sclerosis measured with $7 \mathrm{~T}$ quantitative susceptibility mapping correlates with inhibitory control. AJNR Am J Neuroradiol (2016) 37(3):439-46. doi:10.3174/ajnr.A4599

65. Haider L, Simeonidou C, Steinberger G, Hametner S, Grigoriadis N, Deretzi G, et al. Multiple sclerosis deep grey matter: the relation between demyelination, neurodegeneration, inflammation and iron. J Neurol Neurosurg Psychiatry (2014) 85(12):1386-95. doi:10.1136/jnnp-2014-307712

66. Bagnato F, Hametner S, Yao B, van Gelderen P, Merkle H, Cantor FK, et al. Tracking iron in multiple sclerosis: a combined imaging and histopathological study at 7 Tesla. Brain (2011) 134(Pt 12):3602-15. doi:10.1093/brain/ awr278

67. Hametner S, Wimmer I, Haider L, Pfeifenbring S, Bruck W, Lassmann H. Iron and neurodegeneration in the multiple sclerosis brain. Ann Neurol (2013) 74(6):848-61. doi:10.1002/ana.23974
68. Beaumont C, Delaby C. Recyclingiron in normal and pathological states. Semin Hematol (2009) 46(4):328-38. doi:10.1053/j.seminhematol.2009.06.004

69. Nemeth E, Rivera S, Gabayan V, Keller C, Taudorf S, Pedersen BK, et al. IL-6 mediates hypoferremia of inflammation by inducing the synthesis of the iron regulatory hormone hepcidin. J Clin Invest (2004) 113(9):1271-6. doi:10.1172/JCI200420945

70. Wessling-Resnick M. Iron homeostasis and the inflammatory response. Annu Rev Nutr (2010) 30:105-22. doi:10.1146/annurev.nutr.012809.104804

71. Schaible UE, Kaufmann SH. Iron and microbial infection. Nat Rev Microbiol (2004) 2(12):946-53. doi:10.1038/nrmicro1046

72. Matak P, Chaston TB, Chung B, Srai SK, McKie AT, Sharp PA. Activated macrophages induce hepcidin expression in $\mathrm{HuH7}$ hepatoma cells. Haematologica (2009) 94(6):773-80. doi:10.3324/haematol.2008.003400

73. Wallace DF. The regulation of iron absorption and homeostasis. Clin Biochem $\operatorname{Rev}(2016)$ 37(2):51-62.

74. Kroner A, Greenhalgh AD, Zarruk JG, Passos Dos Santos R, Gaestel M, David S. TNF and increased intracellular iron alter macrophage polarization to a detrimental M1 phenotype in the injured spinal cord. Neuron (2014) 83(5):1098-116. doi:10.1016/j.neuron.2014.07.027

75. Sindrilaru A, Peters T, Wieschalka S, Baican C, Baican A, Peter H, et al. An unrestrained proinflammatory M1 macrophage population induced by iron impairs wound healing in humans and mice. JClin Invest (2011) 121(3):985-97. doi:10.1172/JCI44490

76. Xiong $\mathrm{S}$, She H, Sung CK, Tsukamoto H. Iron-dependent activation of NF-kappaB in Kupffer cells: a priming mechanism for alcoholic liver disease. Alcohol (2003) 30(2):107-13. doi:10.1016/S0741-8329(03)00100-9

77. Minagar A, Alexander JS. Blood-brain barrier disruption in multiple sclerosis. Mult Scler (2003) 9(6):540-9. doi:10.1191/1352458503ms965oa

78. Grossman RI, Gonzalez-Scarano F, Atlas SW, Galetta S, Silberberg DH. Multiple sclerosis: gadolinium enhancement in MR imaging. Radiology (1986) 161(3):721-5. doi:10.1148/radiology.161.3.3786722

79. McFarland HF, Frank JA, Albert PS, Smith ME, Martin R, Harris JO, et al. Using gadolinium-enhanced magnetic resonance imaging lesions to monitor disease activity in multiple sclerosis. Ann Neurol (1992) 32(6):758-66. doi:10.1002/ana.410320609

80. Hagens M, van Berckel B, Barkhof F. Novel MRI and PET markers of neuroinflammation in multiple sclerosis. Curr Opin Neurol (2016) 29(3):229-36. doi:10.1097/WCO.0000000000000326

81. Vellinga MM, Oude Engberink RD, Seewann A, Pouwels PJ, Wattjes MP, van der Pol SM, et al. Pluriformity of inflammation in multiple sclerosis shown by ultra-small iron oxide particle enhancement. Brain (2008) 131(Pt 3):800-7. doi:10.1093/brain/awn009

82. Absinta M, Sati P, Reich DS. Advanced MRI and staging of multiple sclerosis lesions. Nat Rev Neurol (2016) 12(6):358-68. doi:10.1038/nrneurol.2016.59

83. Pitt D, Boster A, Pei W, Wohleb E, Jasne A, Zachariah CR, et al. Imaging cortical lesions in multiple sclerosis with ultra-high-field magnetic resonance imaging. Arch Neurol (2010) 67(7):812-8. doi:10.1001/ archneurol.2010.148

84. Walsh AJ, Lebel RM, Eissa A, Blevins G, Catz I, Lu JQ, et al. Multiple sclerosis: validation of MR imaging for quantification and detection of iron. Radiology (2013) 267(2):531-42. doi:10.1148/radiol.12120863

85. Wang Y, Liu T. Quantitative susceptibility mapping (QSM): decoding MRI data for a tissue magnetic biomarker. Magn Reson Med (2015) 73(1):82-101. doi: $10.1002 / \mathrm{mrm} .25358$

86. Moon Y, Han SH, Moon WJ. Patterns of Brain iron accumulation in vascular dementia and Alzheimer's dementia using quantitative susceptibility mapping imaging. J Alzheimers Dis (2016) 51(3):737-45. doi:10.3233/JAD-151037

87. Doring TM, Granado V, Rueda F, Deistung A, Reichenbach JR, Tukamoto G, et al. Quantitative susceptibility mapping indicates a disturbed brain iron homeostasis in neuromyelitis optica - a pilot study. PLoS One (2016) 11(5):e0155027. doi:10.1371/journal.pone.0155027

88. PoyntonCB, JenkinsonM,AdalsteinssonE,SullivanEV,Pfefferbaum A, WellsW III. Quantitative susceptibility mapping by inversion of a perturbation field model: correlation with brain iron in normal aging. IEEE Trans Med Imaging (2015) 34(1):339-53. doi:10.1109/TMI.2014.2358552

89. Barbosa JH, Santos AC, Tumas V, Liu M, Zheng W, Haacke EM, et al. Quantifying brain iron deposition in patients with Parkinson's disease using quantitative susceptibility mapping, R2 and R2. Magn Reson Imaging (2015) 33(5):559-65. doi:10.1016/j.mri.2015.02.021 
90. Zheng W, Nichol H, Liu S, Cheng YC, Haacke EM. Measuring iron in the brain using quantitative susceptibility mapping and X-ray fluorescence imaging. Neuroimage (2013) 78:68-74. doi:10.1016/j.neuroimage.2013.04.022

91. Lim IA, Faria AV, Li X, Hsu JT, Airan RD, Mori S, et al. Human brain atlas for automated region of interest selection in quantitative susceptibility mapping: application to determine iron content in deep gray matter structures. Neuroimage (2013) 82:449-69. doi:10.1016/j.neuroimage.2013.05.127

92. Langkammer C, Krebs N, Goessler W, Scheurer E, Ebner F, Yen K, et al. Quantitative MR imaging of brain iron: a postmortem validation study. Radiology (2010) 257(2):455-62. doi:10.1148/radiol.10100495

93. Bilgic B, Pfefferbaum A, Rohlfing T, Sullivan EV, Adalsteinsson E. MRI estimates of brain iron concentration in normal aging using quantitative susceptibility mapping. Neuroimage (2012) 59(3):2625-35. doi:10.1016/j. neuroimage.2011.08.077

94. Tan H, Zhang L, Mikati AG, Girard R, Khanna O, Fam MD, et al. Quantitative susceptibility mapping in cerebral cavernous malformations: clinical correlations. AJNR Am J Neuroradiol (2016) 37(7):1209-15. doi:10.3174/ajnr.A4724

95. Ogasawara A, Kakeda S, Watanabe K, Ide S, Ueda I, Murakami Y, et al. Quantitative susceptibility mapping in patients with systemic lupus erythematosus: detection of abnormalities in normal-appearing basal ganglia. Eur Radiol (2016) 26(4):1056-63. doi:10.1007/s00330-015-3929-3

96. Du G, Liu T, Lewis MM, Kong L, Wang Y, Connor J, et al. Quantitative susceptibility mapping of the midbrain in Parkinson's disease. Mov Disord (2016) 31(3):317-24. doi:10.1002/mds.26417

97. Bian W, Tranvinh E, Tourdias T, Han M, Liu T, Wang Y, et al. In vivo 7T MR quantitative susceptibility mapping reveals opposite susceptibility contrast between cortical and white matter lesions in multiple sclerosis. AJNR Am J Neuroradiol (2016). doi:10.3174/ajnr.A4830

98. Schweitzer AD, Liu T, Gupta A, Zheng K, Seedial S, Shtilbans A, et al. Quantitative susceptibility mapping of the motor cortex in amyotrophic lateral sclerosis and primary lateral sclerosis. AJR Am J Roentgenol (2015) 204(5):1086-92. doi:10.2214/AJR.14.13459

99. Murakami Y, Kakeda S, Watanabe K, Ueda I, Ogasawara A, Moriya J, et al. Usefulness of quantitative susceptibility mapping for the diagnosis of Parkinson disease. AJNR Am J Neuroradiol (2015) 36(6):1102-8. doi:10.3174/ ajnr.A4260

100. Eskreis-Winkler S, Deh K, Gupta A, Liu T, Wisnieff C, Jin M, et al. Multiple sclerosis lesion geometry in quantitative susceptibility mapping (QSM) and phase imaging. J Magn Reson Imaging (2015) 42(1):224-9. doi:10.1002/ jmri.24745

101. He N, Ling H, Ding B, Huang J, Zhang Y, Zhang Z, et al. Region-specific disturbed iron distribution in early idiopathic Parkinson's disease measured by quantitative susceptibility mapping. Hum Brain Mapp (2015) 36(11):4407-20. doi:10.1002/hbm.22928

102. Liu T, Spincemaille P, de Rochefort L, Wong R, Prince M, Wang Y. Unambiguous identification of superparamagnetic iron oxide particles through quantitative susceptibility mapping of the nonlinear response to magnetic fields. Magn Reson Imaging (2010) 28(9):1383-9. doi:10.1016/ j.mri.2010.06.011

103. Li W, Wu B, Liu C. Quantitative susceptibility mapping of human brain reflects spatial variation in tissue composition. Neuroimage (2011) 55(4):1645-56. doi:10.1016/j.neuroimage.2010.11.088

104. Wisnieff C, Ramanan S, Olesik J, Gauthier S, Wang Y, Pitt D. Quantitative susceptibility mapping (QSM) of white matter multiple sclerosis lesions: interpreting positive susceptibility and the presence of iron. Magn Reson Med (2015) 74(2):564-70. doi:10.1002/mrm.25420

105. Tan H, Liu T, Wu Y, Thacker J, Shenkar R, Mikati AG, et al. Evaluation of iron content in human cerebral cavernous malformation using quantitative susceptibility mapping. Invest Radiol (2014) 49(7):498-504. doi:10.1097/ RLI.0000000000000043
106. Popescu BF, Frischer JM, Webb SM, Tham M, Adiele RC, Robinson CA, et al. Pathogenic implications of distinct patterns of iron and zinc in chronic MS lesions. Acta Neuropathol (2017) 134(1):45-64. doi:10.1007/s00401-017-1696-8

107. Langkammer C, Liu T, Khalil M, Enzinger C, Jehna M, Fuchs S, et al. Quantitative susceptibility mapping in multiple sclerosis. Radiology (2013) 267(2):551-9. doi:10.1148/radiol.12120707

108. Wiggermann V, Hametner S, Hernández-Torres E, Kames C, Endmayr V, Kasprian G, et al. Susceptibility-sensitive MRI of multiple sclerosis lesions and the impact of normal-appearing white matter changes. NMR Biomed (2017) 30(8). doi:10.1002/nbm.3727

109. Birkl C, Carassiti D, Hussain F. Assessment of ferritin content in multiple sclerosis brains using temperature-induced $\mathrm{R}^{\star} 2$ changes. Magn Reson Med (2017) 79(3):1609-15. doi:10.1002/mrm.26780

110. Liu Z, Spincemaille P, Yao Y, Zhang Y, Wang Y. MEDI+0: morphology enabled dipole inversion with automatic uniform cerebrospinal fluid zero reference for quantitative susceptibility mapping. Magn Reson Med (2017). doi:10.1002/mrm.26946

111. Chen W, Gauthier SA, Gupta A, Comunale J, Liu T, Wang S, et al. Quantitative susceptibility mapping of multiple sclerosis lesions at various ages. Radiology (2014) 271(1):183-92. doi:10.1148/radiol.13130353

112. Zhang Y, Gauthier SA, Gupta A, Comunale J, Chia-Yi Chiang G, Zhou D, et al. Longitudinal change in magnetic susceptibility of new enhanced multiple sclerosis (MS) lesions measured on serial quantitative susceptibility mapping (QSM). J Magn Reson Imaging (2016) 44(2):426-32. doi:10.1002/ jmri.25144

113. Absinta M, Sati P, Schindler M, Leibovitch EC, Ohayon J, Wu T, et al. Persistent 7-tesla phase rim predicts poor outcome in new multiple sclerosis patient lesions. J Clin Invest (2016) 126(7):2597-609. doi:10.1172/JCI86198

114. Sinnecker T, Schumacher S, Mueller K, Pache F, Dusek P, Harms L, et al. MRI phase changes in multiple sclerosis vs neuromyelitis optica lesions at 7T. Neurol Neuroimmunol Neuroinflamm (2016) 3(4):e259. doi:10.1212/ NXI.0000000000000259

115. Yao Y, Nguyen TD, Pandya S, Zhang Y, Hurtado Rua S, Kovanlikaya I, et al. Combining Quantitative Susceptibility Mapping with Automatic Zero Reference (QSM0) and Myelin Water Fraction Imaging to Quantify Iron-Related Myelin Damage in Chronic Active MS Lesions. AJNR Am J Neuroradiol (2018) 39(2):303-10. doi:10.3174/ajnr.A5482

116. Mishra MK, Wang J, Keough MB, Fan Y, Silva C, Sloka S, et al. Laquinimod reduces neuroaxonal injury through inhibiting microglial activation. Ann Clin Transl Neurol (2014) 1(6):409-22. doi:10.1002/acn3.67

117. Durafourt BA, Lambert C, Johnson TA, Blain M, Bar-Or A, Antel JP. Differential responses of human microglia and blood-derived myeloid cells to FTY720. J Neuroimmunol (2011) 230(1-2):10-6. doi:10.1016/ j.jneuroim.2010.08.006

118. Comi G, Pulizzi A, Rovaris M, Abramsky O, Arbizu T, Boiko A, et al. Effect of laquinimod on MRI-monitored disease activity in patients with relapsing-remitting multiple sclerosis: a multicentre, randomised, double-blind, placebo-controlled phase IIb study. Lancet (2008) 371(9630):2085-92. doi:10.1016/S0140-6736(08)60918-6

Conflict of Interest Statement: The authors declare that the research was conducted in the absence of any commercial or financial relationships that could be construed as a potential conflict of interest.

Copyright $\odot 2018$ Gillen, Mubarak, Nguyen and Pitt. This is an open-access article distributed under the terms of the Creative Commons Attribution License (CC $B Y)$. The use, distribution or reproduction in other forums is permitted, provided the original author(s) and the copyright owner are credited and that the original publication in this journal is cited, in accordance with accepted academic practice. No use, distribution or reproduction is permitted which does not comply with these terms. 